\title{
PLANOS MUNICIPAIS DE SANEAMENTO BÁSICO: ESTRATÉGIAS DE EDUCAÇÃO AMBIENTAL
}

\author{
Vinicius Tischer ${ }^{1}$
}

Resumo: Atualmente, um processo grandioso de planejamento sobre o saneamento básico tem sido desencadeado no país, a concepção de Planos Municipais de Saneamento Básico, principalmente, pelas políticas públicas nacionais de Saneamento e de Resíduos Sólidos, e que para ter acesso a recursos o município precisa aprovar seu plano. Como premissas destas políticas é prevista a ampla participação social. Entretanto, observa-se que a participação social efetiva nem sempre ocorre. A proposta do trabalho visa fornecer estratégias de Educação Ambiental voltadas, de forma prática, para a participação e sensibilização da população municipal nesse processo. Foram desenvolvidos dois programas que mostraram um caminho de controle social e melhoria da qualidade de vida.

Palavras-chave: Plano Municipal de Saneamento Básico; Educação Ambiental; Gestão e Planejamento Ambiental.

\footnotetext{
${ }^{1}$ Ecolibra Engenharia Projetos e Sustentabilidade, Balneário Camboriú, SC.

E-mail: viniciustischer@hotmail.com

revista brasileira educação ambiental 


\section{Introdução}

Muito vem se discutindo acerca do defasado sistema de saneamento básico das cidades, de sua influência negativa para o turismo, gargalo para o desenvolvimento municipal, e outros mais. Percebe-se, entretanto, um desvio de interesse da população e a falta de informação, já que poucos sabem que saneamento se refere ao conjunto das infraestruturas de abastecimento de água, esgotamento sanitário, drenagem pluvial e manejo de resíduos sólidos. $\mathrm{E}$ que para ter acesso a recursos financeiros, o munícipio precisa ter um instrumento de planejamento integrado concebido em um Plano Municipal de Saneamento Básico.

Segundo a OMS o saneamento básico pode ser entendido como controle de fatores do meio físico do ser humano que podem vir a interferir no bem-estar físico, mensal e social (PHILIPPI JR.; MALHEIROS, 2005). Assim o saneamento tem por objetivo melhorar a qualidade de vida da população e minimizar impactos negativos ao meio ambiente.

A Organização Mundial da Saúde e UNICEF (WHO; UNICEF, 2008) acrescenta que a importância do saneamento é indiscutível, representando um passo fundamental para melhorar a saúde: o saneamento oferece a oportunidade de salvar a vida de 1,5 milhão de crianças por ano, sendo o total de crianças que sucumbem por doenças diarreicas, além de proteger a saúde de muitos mais. Sem saneamento básico, as pessoas sofrem de problemas de saúde, os rendimentos são diminuídos, e causam inconvenientes e indignidade.

Merece destaque ainda, os benefícios econômicos, onde os investimentos em saneamento protegem os investimentos feitos em outros setores, como educação e saúde, e trazem retornos econômicos mensuráveis.

Nesse sentido, os Planos Municipais de Saneamento Básico estão aumentando sua representatividade por entre os municípios brasileiros. A principal razão motivadora para isso é a pressão governamental para o atendimento ao estabelecido na Lei do Saneamento, instituída pela Lei 11.445/2007, a qual aborda as diretrizes para alcançar a dita universalização dos serviços de saneamento no país estabelecendo prazos para os municípios aprovarem seus planos.

Essa discussão foi reforçada recentemente pela Política Nacional dos Resíduos Sólidos (Lei 12.305/2010) que impõe que a disposição final ambientalmente adequada dos rejeitos deverá ser feita até o ano de 2014, deixando claro o problema ambiental causado pelos lixões e outras formas não controladas de disposição de resíduos sólidos.

Entretanto, os procedimentos e planejamento contido nos Planos Municipais de Saneamento Básico (PMSB) por vezes não são efetivados, e o sucesso das ações propostas não alcança a eficiência idealizada. Muito disto é proveniente da falta de participação social.

Como prerrogativas da implementação de um plano municipal de saneamento está a ampla participação social que pode ser feita através de 
variados mecanismos como: palestras e divulgação de conhecimentos sobre o saneamento básico, participação em projetos técnicos sociais, fiscalização informal do andamento das obras e atividades, e a participação em demais espaços de consultas públicas, sendo um momento de rico entendimento de problemas regionais e elucidação de dúvidas.

A Fundação Nacional da Saúde (FUNASA, 2012) estabelece os critérios para a elaboração dos PMSB e tem como balizador a metodologia participativa, objetivando municiar os interessados com informações e orientações, e dessa forma trazer à tona a vivência do planejamento municipal, buscando a universalização dos serviços, a inclusão social nas cidades e a sustentabilidade das ações.

O que é observado, entretanto, é que as práticas de Educação Ambiental se encontram -por vezes- em situações com uma baixa efetividade, e até deixadas alheias dentro do plano de saneamento. Como consequência, muitos empecilhos são encontrados para a eficiência dos serviços de saneamento e para a melhoria da qualidade de vida da população. Em outras palavras, há uma relação direta entre a cultura e/ou educação dos munícipes e o sucesso das estratégias de universalização do saneamento básico.

Ao encontro dessas prospectivas, os planos de saneamento devem possuir estratégias de mobilização social de impacto para as pessoas, para que, de fato venham a participar e contribuir, reportando suas demandas e passem a fiscalizar a efetividade do plano de saneamento em seus municípios.

Para tal, o trabalho teve como objetivo a proposição de um programa de Educação Ambiental voltado ações integrantes de um plano de saneamento, que seja robusto e permita um real envolvimento da sociedade.

\section{O Plano Municipal de Saneamento Básico}

Um PMSB é composto por uma sequência de etapas (Figura 1), as quais refletem um profundo conhecimento sobre as questões do saneamento no município e conhecimento sobre o território municipal relacionadas as intervenções sociais existentes, requerendo um modelo participativo permanente. 


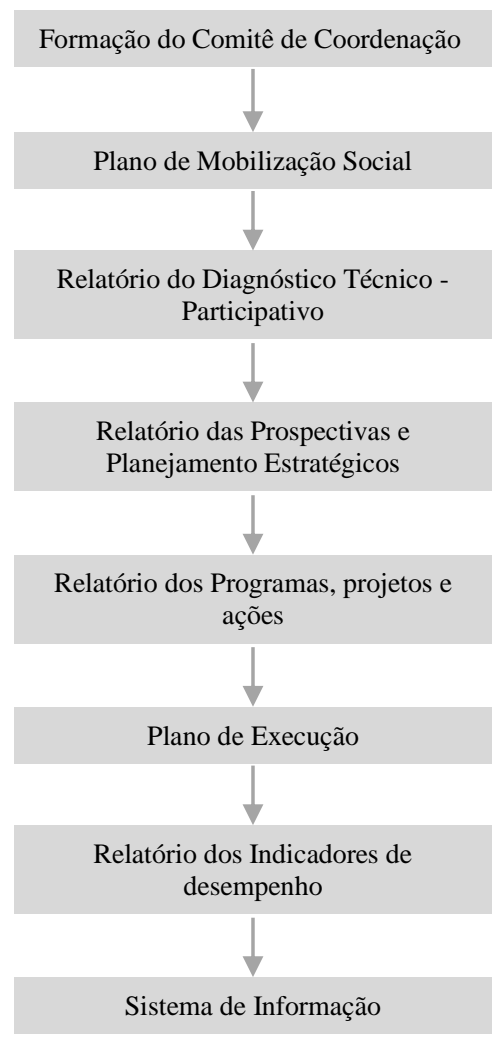

Figura 1: Etapas que compõem um Plano Municipal de Saneamento Básico segundo FUNASA (2012)

A primeira etapa prevê a formação de um Comitê de Coordenação, que representa, segundo a FUNASA (2012) a instância responsável pela operacionalização do processo de elaboração do Plano, composto por membros de órgãos públicos ligados ao saneamento, prestadores de serviços de saneamento e membros da sociedade civil. Este grupo é responsável por discutir, avaliar e aprovar o trabalho produzido pelo Comitê Executivo. Este último grupo é responsável pela operacionalização do processo de elaboração do PMSB, composto por uma equipe multidisciplinar técnica.

Feito essa formação, é necessário a elaboração do Plano de Mobilização Social, onde serão planejados todos os procedimentos, estratégias, mecanismos e metodologias que serão aplicados ao longo de todo o período de elaboração do PMSB para garantir uma participação social ativa. As ações dessa etapa devem permear todo a elaboração do PMSB.

A partir disso inicia-se a fase de diagnóstico abordando as componentes do saneamento (drenagem pluvial, esgotamento sanitário, abastecimento de água e manejo de resíduos sólidos). Este deve fornecer uma avaliação acurada sobre as condições dos serviços, quadro epidemiológico e de saúde, situação socioeconômica, ambiental e institucional.

A etapa de prospectivas e planejamento estratégico ressaltará cenários 
estratégias para resolução das demandas levantadas considerando as incertezas e os riscos envolvidos para alcançar a universalização dos serviços de saneamento.

A partir disso serão estabelecidos programas, projetos e ações de governo para atender aos déficits elencados, compatibilizando, metas, prioridades e compromissos da gestão municipal no atendimento das deficiências nos serviços de saneamento.

Após essa definição deve ser feita uma análise financeira baseada em metas temporais de atendimento das demandas: imediato, curto, médio e longo prazo. Os custos deverão ser estimados considerando as possíveis fontes de financiamento.

As etapas de indicadores de desempenho referem-se definição de indicadores que permitem monitorar a evolução do PMSB em todas as suas etapas de implementação. Sendo o principal objetivo, avaliar o atingimento das metas estabelecidas tanto nos serviços de saneamento como nos aspectos institucionais e de participação social. Associado a isso, tem-se o sistema de informação que é baseado em mecanismos de coleta, tratamento e disponibilização de dados e informações de auxilio no monitoramento da situação do saneamento básico no município.

Mediante essa estrutura, é clarividente a importância da participação social, sendo item determinante para a que, de fato, as melhorias propostas em um plano de saneamento sejam efetivadas e contínuas ao longo do tempo.

\section{Programa de Educação Ambiental - PEA}

O Programa de Educação Ambiental aplicado ao saneamento visa criar de instâncias de participação popular com o objetivo de envolver a comunidade no processo de controle social, não apenas para aspectos vinculados aos serviços de saneamento básico, mas também para estimular a sensibilização e o comprometimento dos populares no processo de transformação de sua realidade, alcançando os níveis mais altos de participação social, que são definidos pelo Ministério das Cidades (MCIDADES, 2011) como esquematizado na Figura 12. 


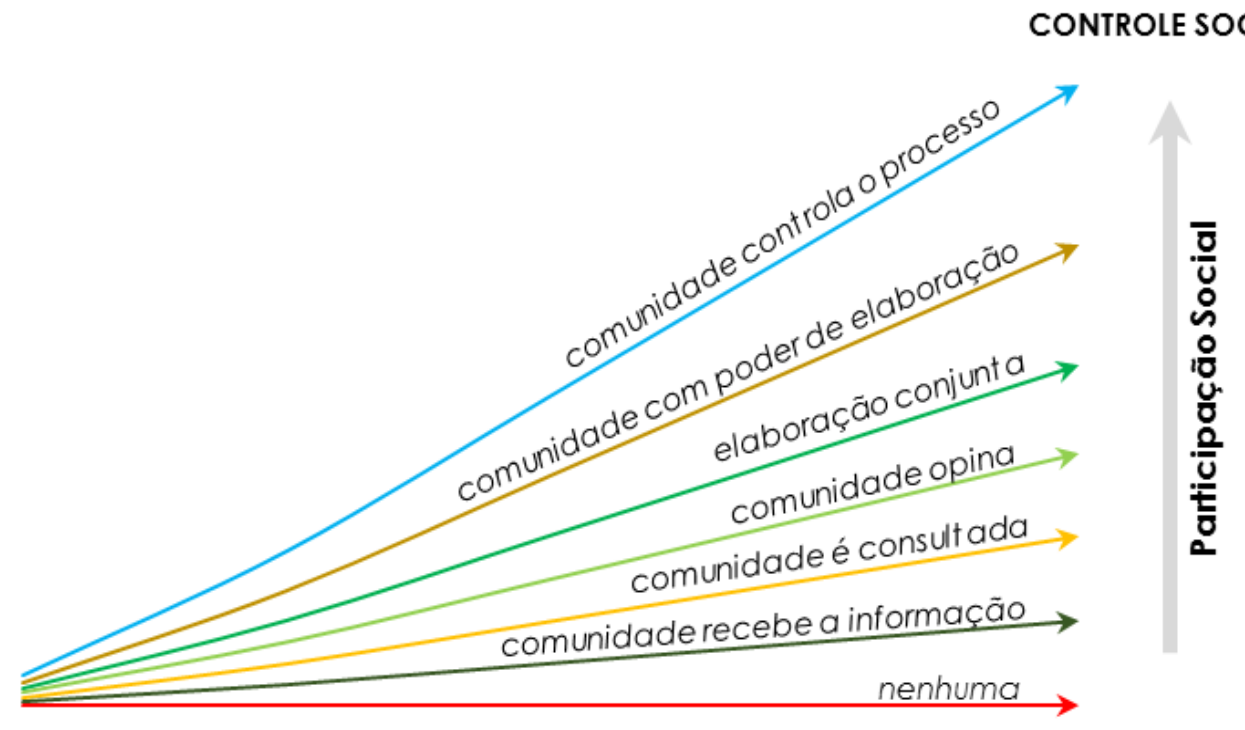

Figura 2: Níveis de participação social e o controle social segundo o MCidades (2011).

Segundo a Política Nacional de Educação Ambiental (Lei 9.795/1999), é incumbido ao Poder Público, inclusive municipal, incentivar a difusão, por intermédio dos meios de comunicação de massa, de programas e campanhas educativas, e de informações acerca de temas relacionados ao meio ambiente; e a ampla participação das escolas, e de organizações não governamentais na formulação e execução de programas e atividades vinculadas à Educação Ambiental não formal.

Mediante isso, o programa de Educação Ambiental, além de mediar as políticas públicas nacionais de saneamento, meio ambiente e de Educação Ambiental, visa disseminar práticas de participação e integração da comunidade aos assuntos de interesse coletivo além de expandir o nível de conhecimento da sociedade sobre a importância do saneamento básico.

Entre os aspectos estratégicos ressalta-se a formação (informal) de agentes multiplicadores. Estes possuem habilidades de transmissão das informações de interesse e agregar o número de sensibilizados sobre a Educação Ambiental Figura 3. 


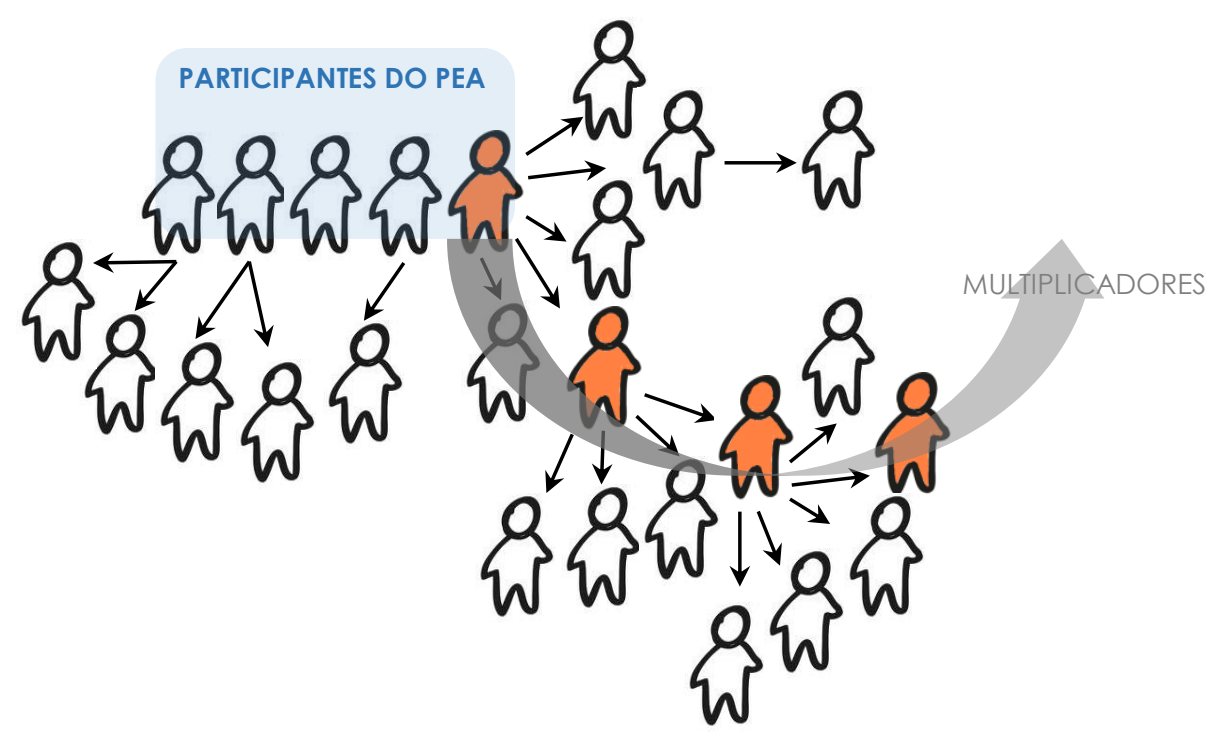

Figura 3: Fluxo de participação social utilizado como estratégia de sensibilização por meio de multiplicadores.

Para atender a essas demandas de um plano de saneamento é necessário que seja motivado o envolvimento prática da população, assim como a ampliação do conhecimento desta por meio de educação forma e informal.

Estes dois fatores permearam a estratégia metodológica do programa de Educação Ambiental proposto. Para tal foi desenvolvido dois projetos que possibilitam atender tanto a educação informal como formal. Estes foram formalmente denominados de: Projeto de Educação em Saúde e Saneamento e; Projeto da Oficina Municipal de Saneamento.

\section{Projeto de Educação em Saúde e Saneamento}

O objeto deste projeto é a conscientização da comunidade por meio de ações junto a grupos sociais desenvolvendo trabalhos informativos na comunidade e pedagógicos nas escolas através de capacitação e cursos para professores, além de seminário anual com palestras sobre saneamento e saúde, contando com autoridades locais para ministrá-las. A forma de intervenção nas escolas pode evoluir ao longo tempo, integrando uma política permanente do governo municipal, incluindo a Educação Ambiental como disciplina obrigatória na grade de ensino escolar.

Deverá ser previsto o envolvimento dos catadores de materiais recicláveis no processo de Educação Ambiental. Para tal será previsto um trabalho de educação voltado à situação socioeconômica da classe e as possibilidades de melhoria de via, ressaltando-se as proposições do município para a gestão dos resíduos sólidos, formação de cooperativas e subsídios municipais.

$O$ trabalho junto às escolas municipais, tendo os professores como foco possui uma importância determinante dentro das atividades de Educação Ambiental. Sendo estes, os transmissores do conhecimento para as crianças e 
adolescentes, que contribuirão diretamente para a interdisciplinaridade do saneamento básico, expondo os alunos de forma criativa e pedagógica a atividades ambientais educacionais. A capacitação deverá abordar além de conceitos teóricos sobre saneamento e meio ambiente, atividades instigadoras às práticas sustentáveis, como mostrado na

Tabela 1.

Também, é contemplado campanhas promovidas pela Secretaria Municipal de Saúde em locais estratégicos do município, com exposições, atividades e outras estratégias de sensibilização a população. Para uma maior cobertura populacional desta estratégia será concebida uma capacitação para os Agentes Comunitários de Saúde para abordarem o tema durante a visita a domicílios do município.

Tabela 1: Atividades sugeridas para práticas do Projeto de Educação em Saúde e Saneamento

\begin{tabular}{|c|c|}
\hline $\begin{array}{l}\text { Público Alvo do } \\
\text { Projeto }\end{array}$ & Sugestões de atividades práticas \\
\hline \multirow{5}{*}{$\begin{array}{l}\text { Alunos, } \\
\text { Professores e } \\
\text { Escolas }\end{array}$} & - $\quad$ Proposição de jornal estudantil feito pelos alunos \\
\hline & Princípios dos 3R's \\
\hline & - $\quad$ Atividades de Planejamento Territorial Municipal \\
\hline & $\begin{array}{l}\text { - Propostas de Revitalização e gestão de recursos } \\
\text { hídricos }\end{array}$ \\
\hline & - Banco de dados de espécies da fauna e flora municipal \\
\hline \multirow{8}{*}{ Comunidade } & - $\quad$ Cidades Sustentáveis \\
\hline & - $\quad$ Agroecologia \\
\hline & - $\quad$ Princípios dos 3R's \\
\hline & $\begin{array}{l}\text { - Atividades de trilhas, ciclismo em ambientes naturais e } \\
\text { visitas em Estações de Tratamento de Água e Efluente }\end{array}$ \\
\hline & $\begin{array}{l}\text { - Aulas de culinária de reaproveitamento e alimentação } \\
\text { saudável e desenvolvimento de hortas comunitárias e } \\
\text { alternativas de irrigação }\end{array}$ \\
\hline & $\begin{array}{l}\text { - Criação de Associações e fóruns de discussão } \\
\text { comunitários }\end{array}$ \\
\hline & $\begin{array}{l}\text { - Geração de emprego e renda e Arranjos Produtivos } \\
\text { Locais - APL }\end{array}$ \\
\hline & $\begin{array}{l}\text { - O papel do catador de materiais na economia municipal } \\
\text { - } \quad \text { Associações entre catadores, agregação de valor e } \\
\text { aumento de renda }\end{array}$ \\
\hline \multirow{4}{*}{$\begin{array}{l}\text { Comunidade } \\
\text { (Campanhas de } \\
\text { Saúde) }\end{array}$} & - Doenças relacionadas da falta de saneamento \\
\hline & - $\quad$ Vetores de doenças \\
\hline & - Riscos ocupacionais para catadores de materiais \\
\hline & $\begin{array}{l}\text { - Explanação sobre a composição química e biológica do } \\
\text { esgoto e da água não tratada (efeitos nos humanos) }\end{array}$ \\
\hline
\end{tabular}

As estratégias educativas terão que manter uma periodicidade, como a sugerida na Tabela 2, para que este processo seja fortalecido e tomado como um hábito a população municipal. Assim, foi sugerido que os trabalhos com a Revbea, São Paulo, V.11, № 2: 203-215, 2016. 
comunidade possam ser bimestrais, com professores mensais e as campanhas de saúde a cada três meses.

Tabela 2: Cronograma físico sugerido para a realização das atividades de Educação Ambiental

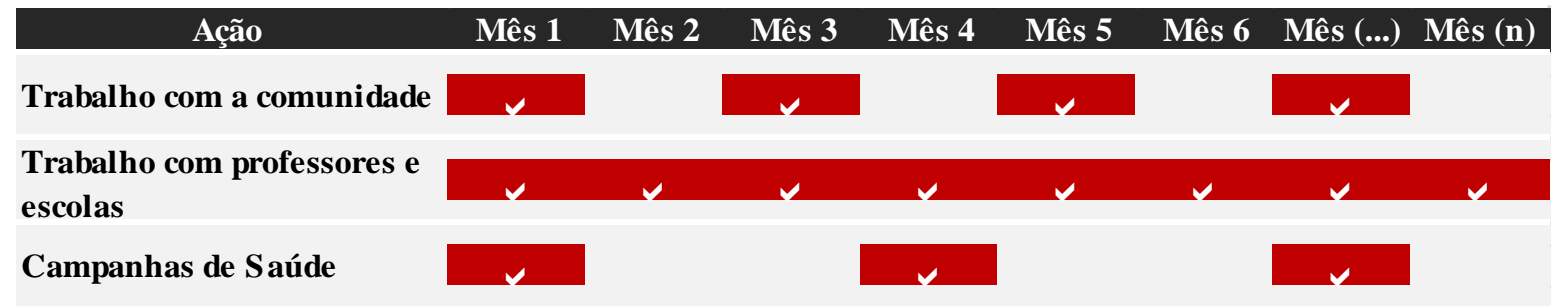

As ações correspondentes ao projeto de Educação em Saúde e Saneamento são correlacionadas como mostrado pelo fluxograma na Figura 4. Sendo de responsabilidade das Secretarias Municipais de Educação e Saúde e de Saneamento. A fiscalização deverá ser feita pela própria Prefeitura Municipal, pelos Conselhos Municipais existentes e pela sociedade civil.

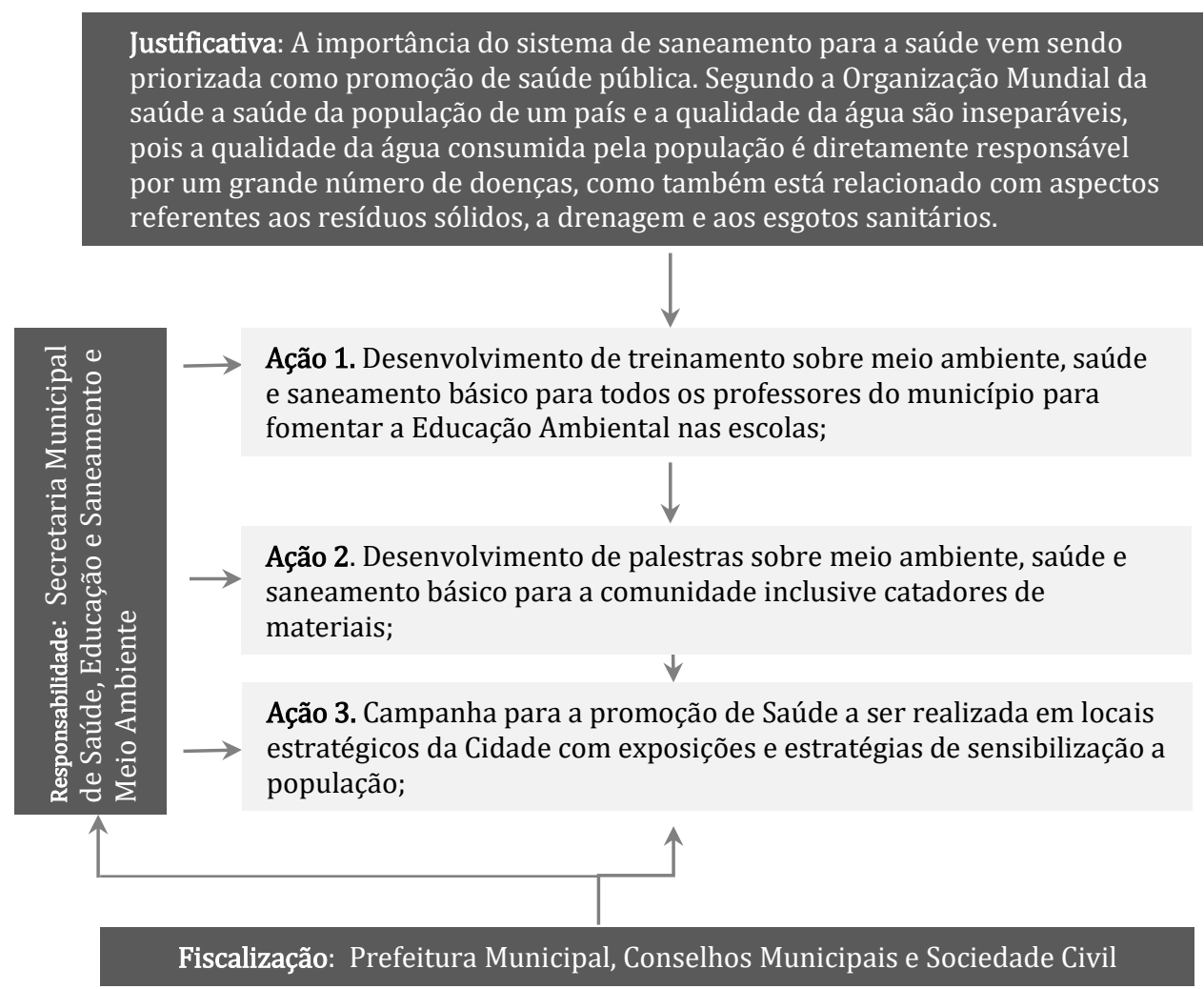

Figura 4: Fluxograma de relação entre o Projeto de Educação em Saúde e Saneamento.

\section{Projeto de Oficina Municipal de Saneamento}

A proposta da Oficina Municipal de Saneamento foi baseada no subsídio financeiro dado pela Funasa para soluções de baixo custo em saneamento. 
Segundo a FUNASA (2006) estas oficinas constituem possuem o objetivo de proporcionar melhorias nos domicílios como: ligações do domicílio à rede pública de água e esgoto, construção de poços rasos, cisternas, privadas, banheiros, fossas, tanques sépticos, instalação de caixa d'água, pia de cozinha, tanque de lavar roupa e melhorias coletivas de pequeno porte, entre outras.

Com base nesta metodologia, desenvolveu-se uma proposta de Oficina Municipal de Saneamento com um escopo mais amplo para que além de promover melhorias sanitárias, represente uma unidade de engajamento social, Educação Ambiental e promova a geração de emprego e renda.

A Oficina do Saneamento pode servir de espaço criativo, estimulando discussões sobre as questões de saneamento ambiental no município, buscando de alternativas de soluções viáveis através de estudos de caso e culminando no engajamento social para a melhoria da qualidade de vida da população, como mostrado no esquema apresentado na Figura 5.

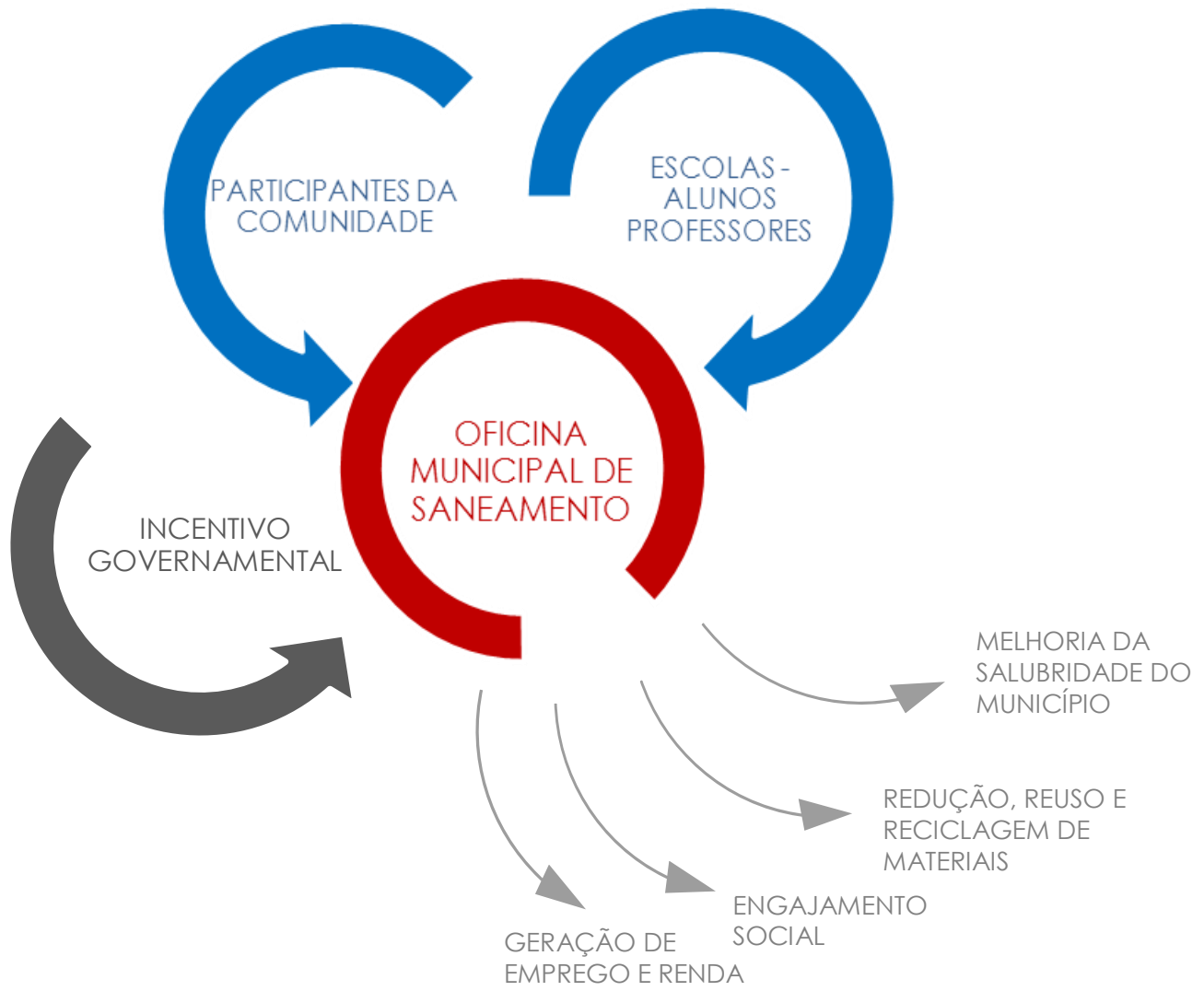

Figura 5: Atores inseridos e resultados esperados da Oficina Municipal de Saneamento de Sossego.

Para operacionalização desta oficina é necessário à constituição de espaço físico, dotado de recursos materiais, equipamentos e profissionais capacitados em saneamento, com objetivo de desenvolver atividades e formação de grupos específicos capacitados para a realização de: 
- Melhorias sanitárias domiciliares e coletivas e desenvolvimento de sistemas simplificados de esgotamento sanitário;

- Tecnologias alternativas de baixo custo para o abastecimento de água;

- Reciclagem e reutilização de resíduos sólidos;

- Ações de revitalização cursos d'água e vigilância ambiental.

A Oficina deverá fundada em um espaço físico com equipamentos necessários além de contar com tutor capacitado para coordenar o desenvolvimento das atividades. Entre as atividades da Oficina, foi proposta a seguinte ementa, apresentada na Tabela 3.

Tabela 3: Temas abordados pela Oficina Municipal de Saneamento.

\section{Ação}

Melhorias sanitárias domiciliares e coletivas e desenvolvimento de sistemas simplificados de esgotamento sanitário

\section{Tema abordado}

- Construção de banheiros e unidades sanitárias

- Construção de sistema modular de tratamento individual de esgoto

- Fossa séptica, filtros anaeróbios

- Sistemas de tratamento alternativo de baixo custo

- Construção de cisternas e captação de água pluvial

Tecnologias alternativas de baixo custo para o abastecimento de água

- Poços freáticos

- Barragens subterrâneas e mandalas

- Uso racional de água e irrigação

- Beneficiamento de materiais recicláveis

Reciclagem e reutilização de resíduos sólidos

- Técnicas de agregação de valor em resíduos sólidos

- Técnicas de reciclagem de materiais

- Salubridade ambiental

Ações de revitalização cursos d'água e vigilância ambiental
- Conforto ambiental

- Técnicas de revitalização de copos hídricos e utilização da engenharia de biossitemas

- Fontes difusas de contaminação.

As oficinas serão gratuitas, sendo os recursos provenientes do firmamento de parcerias, doações municipais ou comercialização de produtos, e também por convênios firmados com a FUNASA por meio da submissão de projeto técnico da Oficina Municipal de Saneamento. Poderão ser adotados mecanismos de incentivo para participantes assim como cobrança de desempenho escolar mínimo. As ações e responsabilidades do Programa de Educação Ambiental são detalhadas no fluxograma apresentado na Figura 6. 
Justificativa: A carência de ações de saúde e saneamento no município ameaçam a qualidade e de vida da população municipal. Assim, o projeto visa dar subsídios à vigilância ambiental em saúde e ao desenvolvimento das ações de saneamento, mais especificamente àquelas relacionadas às melhorias sanitárias domiciliares, técnicas de aproveitamento de água e de reutilização e reciclagem de materiais

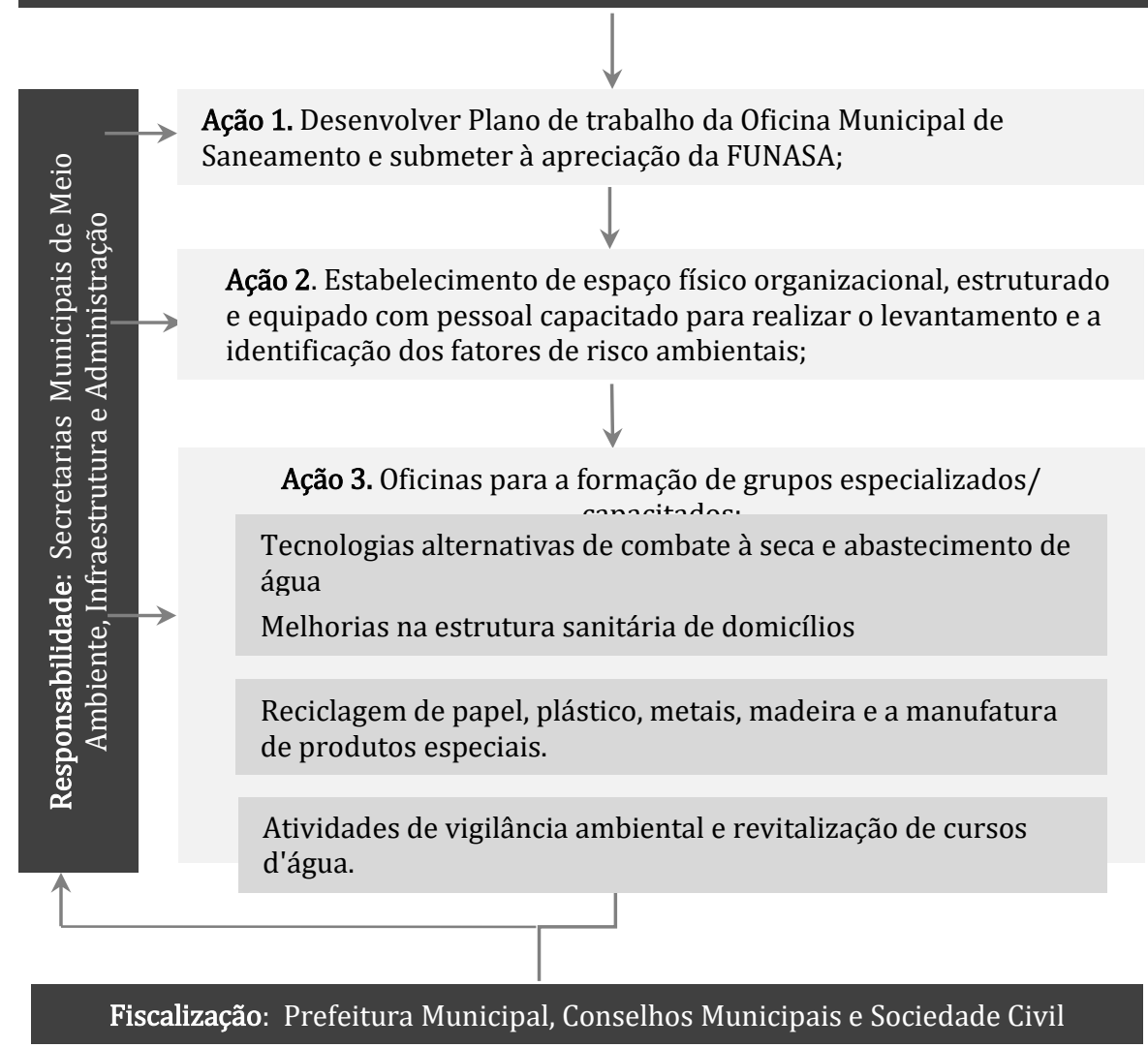

Figura 6: Fluxograma de relação entre as ações do Projeto da Oficina Municipal de Saneamento Básico.

Entre as ações e propostas estão atividades que enfocam a reciclagem e reutilização de materiais recicláveis, que promovam atividades relativas ao processo de reciclagem de papel, plástico, metais, madeira, entulhos e a manufatura de produtos especiais. Nesse processo, os catadores de materiais possuem um papel preponderante, podendo integrar-se nas atividades da oficina mediante a realização de capacitação necessária.

\section{Conclusão}

Um projeto efetivo melhoria na qualidade ambiental será alcançada a partir do momento em que a população possuir ciência de que as questões de saneamento básico, saúde e integridade de ecossistemas estão diretamente relacionadas. Nesse contexto, a educação é o ponto de inflexão para o engajamento e a mobilização social. 
Assim, para haver a participação social é fundamental entender a importância de uma infraestrutura adequada de saneamento básico. E para que haja cidades com melhores chances de prosperar e superar condições insalubres de vida em que parcela da população convive diariamente é necessário que diálogos entre prefeitura, munícipes e empresas parceiras sejam iniciados, pessoas sejam mobilizadas e prioridades definidas e os interesses de mudança, sejam unicamente de caráter coletivo.

Com isso, o estudo buscou trazer ferramentas sob uma perspectiva integrada, onde uma atividade suporta a outra e o engajamento social será decisivo no sucesso das ações propostas, e também em outras áreas de atuação do município.

A aliança entre o ensino formal que contemple todas as escolas do município pode contribuir para o desenvolvimento de cidadãos mais críticos e comprometidos, ao passo que, a oficina municipal de saneamento permitirá o contato prático dos munícipes com a melhoria do saneamento básico. E permeando esse processo, sempre serão enfatizados os valores de ética, responsabilidade, trabalho em equipe, preservação ambiental, ciclo de vida dos produtos, etc.

Como questão determinante ressalta-se a importância da eficácia institucional, que incumbido da tarefa da tomada de decisão, poderá tornar possível as propostas levantadas neste estudo e utilizando de forma eficiente os recursos conveniados ou disponibilizados.

\section{Referências}

MCIDADES - MINISTÉRIO DAS CIDADES. Os níveis de participação social são definidos pelo Ministério das Cidades. In: Guia para a elaboração de Planos Municipais de Saneamento Básico - Brasília: Ministério das Cidades, 2011. $2^{\mathrm{a}}$ edição.152 p.: il.

FUNASA - FUNDAÇÃO NACIOL DA SAÚDE/ MINISTÉRIO DA SAÚDE. Termo de referência para elaboração de Planos Municipais de Saneamento Básico. Procedimentos relativos ao convênio de cooperação técnica e financeira da Fundação Nacional de Saúde - Funasa/MS. Brasília, 2012.

BRASIL. Lei no 9.795, de 27 de Abril de 1999. Dispõe sobre a Educação Ambiental, institui a Política Nacional de Educação Ambiental e dá outras providências. Brasília, 1999.

PHILIPPI JR, A.; MALHEIROS, T.F. Saneamento e saúde pública: integrando homem e meio ambiente. In: PHILIPPI JR, A. Saneamento saúde e ambiente: fundamentos para um desenvolvimento sustentável. Barueri, SP: Manole, 2005.

UNICEF - WHO - World Health Organization and United Nations Children's Fund Joint. Monitoring Programme for Water Supply and Sanitation (JMP). Progress on Drinking Water and Sanitation: Special Focus on Sanitation. UNICEF, New York and WHO, Geneva, 2008. 